\title{
Flame-Retardant and Thermal Degradation Mechanism of Caged Phosphate Charring Agent with Melamine Pyrophosphate for Polypropylene
}

\author{
Xuejun Lai, Jiedong Qiu, Hongqiang Li, Xingrong Zeng, \\ Shuang Tang, Ye Chen, and Zhen Chen \\ College of Materials Science and Engineering, South China University of Technology, Guangzhou 510640, China \\ Correspondence should be addressed to Xuejun Lai; msxjlai@scut.edu.cn and Xingrong Zeng; psxrzeng@gmail.com
}

Received 8 April 2015; Revised 29 May 2015; Accepted 30 May 2015

Academic Editor: De-Yi Wang

Copyright (C) 2015 Xuejun Lai et al. This is an open access article distributed under the Creative Commons Attribution License, which permits unrestricted use, distribution, and reproduction in any medium, provided the original work is properly cited.

An efficient caged phosphate charring agent named PEPA was synthesized and combined with melamine pyrophosphate (MPP) to flame-retard polypropylene (PP). The effects of MPP/PEPA on the flame retardancy and thermal degradation of PP were investigated by limiting oxygen index (LOI), vertical burning test (UL-94), cone calorimetric test (CCT), and thermogravimetric analysis (TGA). It was found that PEPA showed an outstanding synergistic effect with MPP in flame retardant PP. When the content of PEPA was $13.3 \mathrm{wt} \%$ and MPP was $6.7 \mathrm{wt} \%$, the LOI value of the flame retardant PP was $33.0 \%$ and the UL-94 test was classed as a $\mathrm{V}-0$ rating. Meanwhile, the peak heat release rate (PHRR), average heat release rate (AV-HRR), and average mass loss rate (AV-MLR) of the mixture were significantly reduced. The flame-retardant and thermal degradation mechanism of MPP/PEPA was investigated by TGA, Fourier transform infrared spectroscopy (FTIR), TG-FTIR, and scanning electron microscopy-energy dispersive X-ray spectrometry (SEM-EDXS). It revealed that MPP/PEPA could generate the triazine oligomer and phosphoruscontaining compound radicals which changed the thermal degradation behavior of PP. Meanwhile, a compact and thermostable intumescent char was formed and covered on the matrix surface to prevent PP from degrading and burning.

\section{Introduction}

In recent years, intumescent flame retardants (IFRs) have aroused more and more attention in flame retardant polypropylene (PP), due to their being environmentalfriendly, low smoke and antidripping [1-3]. Typically, an IFR system is composed of three components: an acid source, a charring agent, and a blowing agent [4]. The most reported IFR system is ammonium polyphosphate/pentaerythritol/ melamine (APP/PER/MEL), which was systematically studied by Bourbigot's [5, 6] and Camino's groups [7]. When being burned, the IFR forms an intumescent multicellular char, acting as a physical barrier which slows down the heat and oxygen transfer and thus prevents the substrate from degrading and burning. However, the relatively low flame retardant efficiency, poor thermostability, and high moisture of the IFR system severely impede its actual commercial application [8].
To overcome these shortcomings, it is imperative to develop a new IFR system. One solution is to apply new acid source such as melamine pyrophosphate (MPP) $[9,10]$, which is widely used in flame retardant nylon because of its good thermostability and water-resistance property [11-13]. Another one is to synthesize novel charring agents which possess excellent char-forming capability and good thermostability to substitute PER, such as caged bicyclic phosphates [14-16] and triazine derivatives [17]. Recently, caged bicyclic phosphate 2,6,7-trioxa1-phosphabicyclo[2.2.2] octane-4-methanol 1-oxide, named pentaerythritol phosphate (PEPA) was considered to be one of the most promising halogen-free flame retardants because of its good thermostability and outstanding char-forming capability $[10,11,18]$. Jiao and coworkers $[9,10]$ employed MPP and PEPA to flame-retard PP. It was found that MPP/PEPA could effectively improve the flame retardancy and thermostability of PP. When the content of PEPA and 


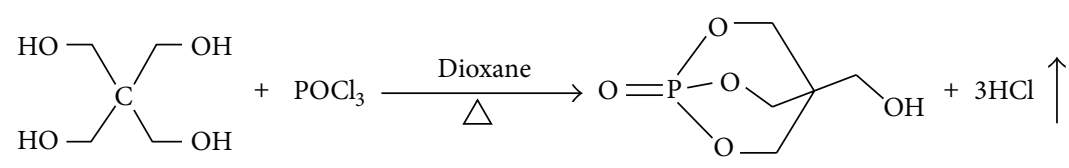

SCHEME 1: Synthetic route of PEPA.

MPP was 15 wt $\%$ and 15 wt $\%$, respectively, the LOI value of the flame retardant PP was 33.2\% and the UL-94 test was classed as a V-0 rating. However, the flame-retardant and thermal degradation mechanism of MPP/PEPA for PP had not been investigated and revealed.

In this work, an efficient caged bicyclic phosphate PEPA was synthesized and combined with MPP to flame-retard PP. The effects of MPP/PEPA on the flame retardancy and thermal degradation of PP were investigated by limiting oxygen index (LOI), vertical burning test (UL-94), cone calorimetric test (CCT), and thermogravimetric analysis (TGA). The flame-retardant and thermal degradation mechanism of MPP/PEPA was investigated and revealed by TGA, Fourier transform infrared spectroscopy (FTIR), TG-FTIR, and scanning electron microscopy-energy dispersive X-ray spectrometry (SEM-EDXS).

\section{Experiment}

2.1. Materials. Polypropylene (PP, T30S, a granulated product with a melt flow index of $3.0 \mathrm{~g} / 10 \mathrm{~min}, 230^{\circ} \mathrm{C}, 2.16 \mathrm{~kg}$ ) was provided by Maoming Petrochemical Co., Ltd., China. Melamine pyrophosphate (MPP) was obtained from Jiangmen Topchem Technology Co., Ltd., China. Pentaerythritol (PER) was purchased from Tianjin Kermel Chemical Reagent Co., Ltd., China. Dioxane and phosphorus oxychloride $\left(\mathrm{POCl}_{3}\right)$ were supplied by Changzheng Chemical Reagent Co., Ltd., China. $\mathrm{POCl}_{3}$ was distilled under atmospheric pressure before use. Ethanol was purchased from Chinasun Specialty Products Co., Ltd., China. Antioxidant (B215) was provided by Ciba Specialty Chemicals Inc., Switzerland. All the commercial materials except $\mathrm{POCl}_{3}$ were used directly without further purification.

2.2. Synthesis of 2,6,7-Trioxa-1-phosphabicyclo[2.2.2]octane-4methanol 1-Oxide Pentaerythritol Phosphate (PEPA). PEPA was synthesized in our laboratory according to Balabanovich's work [19]. Exactly $68.1 \mathrm{~g}(0.5 \mathrm{~mol})$ pentaerythritol, $22.5 \mathrm{~mL}$ of $\mathrm{POCl}_{3}$, and $200 \mathrm{~mL}$ dioxane and aqueous $\mathrm{NaOH}$ solution were added in a $500 \mathrm{~mL}$ round bottom flask. The mixture was stirred and heated up to $85^{\circ} \mathrm{C}$. Another $22.5 \mathrm{~mL}$ of $\mathrm{POCl}_{3}$ was dropped slowly into the flask. Afterwards, the temperature was heated up to $95^{\circ} \mathrm{C}$, and the reaction was kept under reflux until there was no $\mathrm{HCl}$ released. The reaction mixture was then cooled to the room temperature and filtered. The white solid was washed with dioxane and ethanol for several times. After being dried at $100^{\circ} \mathrm{C}$ under vacuum to a constant weight, the white powdery PEPA was obtained (yield: 91.2\%). The synthetic route of PEPA was shown in Scheme 1.
2.3. Preparation of Flame Retardant PP. PP, MPP, and PEPA were dried in a vacuum oven at $100^{\circ} \mathrm{C}$ for $6 \mathrm{~h}$ before use. Then PP, MPP, and PEPA were melt-mixed on a two-roll mill (XK-160, Changzhou Shuangfeng Machinery Factory, China) at $170^{\circ} \mathrm{C}$ for $15 \mathrm{~min}$. The prepared mixtures were hot-pressed at $180^{\circ} \mathrm{C}$ into sheets of suitable thickness and size for the corresponding tests.

\subsection{Measurements}

2.4.1. Fourier Transform Infrared Spectrometry (FTIR). The sample was mixed with $\mathrm{KBr}$ powder and then pressed into a tablet. The FTIR spectrum of the sample was recorded on a Tensor 27 spectrometer (Bruker Optics Inc., Germany) by averaging 16 scans at a resolution of $4 \mathrm{~cm}^{-1}$. The measurement was carried out in the optical range of $4000-400 \mathrm{~cm}^{-1}$.

2.4.2. ${ }^{1} H$ Nuclear Magnetic Resonance Spectrometry $\left({ }^{1} H\right.$ NMR). The ${ }^{1} \mathrm{H}$ NMR spectrum was obtained by using a Bruker AV300 NMR Spectrometer (Bruker, Germany) with $\left(\mathrm{CD}_{3}\right)_{2} \mathrm{SO}$ as a solvent.

2.4.3. Elemental Analysis (EA) and Inductively Coupled Plasma-Atomic Emission Spectrometry (ICP-AES). The element content of the sample was measured by an elemental analyzer (Vario EL cube, Elementar Analysensysteme GmbH, Germany) and an inductively coupled plasma-atomic emission spectrometer (ICAP 6500 Duo, Thermo Fisher Scientific Co., USA).

2.4.4. Thermogravimetric Analysis (TGA). The TGA was carried out with a TG209 thermal analyzer (Netzsch Instruments Co., Germany) from $30^{\circ} \mathrm{C}$ to $700^{\circ} \mathrm{C}$ at a linear heating rate of $20^{\circ} \mathrm{C} / \mathrm{min}$ under an air flow of $30 \mathrm{~mL} / \mathrm{min}$. Each sample was measured in an alumina crucible with a weight about $10 \mathrm{mg}$.

2.4.5. Thermogravimetry-Fourier Transform Infrared Spectrometry (TG-FTIR). The TG-FTIR instrument consists of a thermogravimeter (TG209, Netzsch Instruments Co., Germany), a Fourier transform infrared spectrometer (Tensor 27, Bruker Optics Inc., Germany), and a transfer tube with an inner diameter of $1 \mathrm{~mm}$ connected the TG and the infrared cell. The investigation was carried out from $30^{\circ} \mathrm{C}$ to $750^{\circ} \mathrm{C}$ at a linear heating rate of $20^{\circ} \mathrm{C} / \mathrm{min}$ under a nitrogen flow of $30 \mathrm{~mL} / \mathrm{min}$. In order to reduce the possibility of pyrolysis gas condensing along the transfer tube, the temperature of the infrared cell and transfer tube was set to $230^{\circ} \mathrm{C}$. 


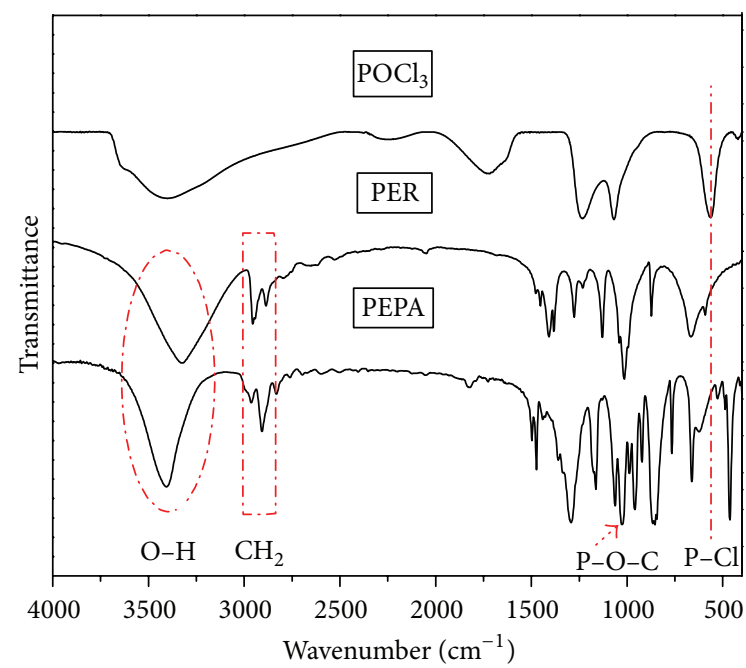

Figure 1: FTIR spectra of $\mathrm{POCl}_{3}$, PER, and PEPA.

2.4.6. Limiting Oxygen Index (LOI). The limiting oxygen index test was measured by using an oxygen index meter (HC-2, Jiangning Analysis Instrument Co., China) according to ASTM D2863-2008. The dimensions of the specimens were $80 \mathrm{~mm} \times 10 \mathrm{~mm} \times 4.0 \mathrm{~mm}$.

2.4.7. Vertical Burning (UL-94) Test. The vertical burning (UL-94) test was conducted on a vertical burn instrument (CFZ-3, Jiangning Analysis Instrument Co., China) according to ASTM 3801-2010. The dimensions of samples were $127 \mathrm{~mm} \times 12.7 \mathrm{~mm} \times 3.2 \mathrm{~mm}$.

2.4.8. Cone Calorimetric Test (CCT). The cone calorimetric test was carried out by a cone calorimeter (Fire Testing Technology Co., UK) according to ISO5660. Each specimen, with the dimensions of $100 \mathrm{~mm} \times 100 \mathrm{~mm} \times 4 \mathrm{~mm}$, was wrapped in aluminum foil and exposed horizontally to an external heat flux of $35 \mathrm{~kW} / \mathrm{m}^{2}$.

2.4.9. Scanning Electron Microscopy-Energy Dispersive X-Ray Spectrometry (SEM-EDXS). The morphology of the residue was observed by a scanning electron microscope (EV0-18, Carl Zeiss Jena Co., Germany) with an accelerating voltage of $20.0 \mathrm{kV}$. The surface of the residue was sputter-coated with a conductive gold layer before observation. EDXS result of the char was measured by an energy dispersive X-ray spectrometer.

\section{Results and Discussion}

3.1. Characterization of PEPA. Figure 1 shows the FTIR spectra of $\mathrm{POCl}_{3}, \mathrm{PER}$, and PEPA. $\mathrm{POCl}_{3}$ was mainly characterized by the absorption of $1200-1300 \mathrm{~cm}^{-1}\left(\nu_{\mathrm{P}=\mathrm{O}}\right)$ and $567 \mathrm{~cm}^{-1}\left(\nu_{\mathrm{P}-\mathrm{Cl}}\right)$. PER was mainly characterized by the peaks of $3390 \mathrm{~cm}^{-1}\left(\nu_{\mathrm{O}-\mathrm{H}}\right)$ and $2960 \mathrm{~cm}^{-1}\left(\nu_{\mathrm{C}-\mathrm{H}}\right)$. When $\mathrm{POCl}_{3}$ reacted with $\mathrm{PER}$, the $\nu_{\mathrm{P}_{-} \mathrm{Cl}}$ peak disappeared, and a new peak appeared at $1019 \mathrm{~cm}^{-1}\left(\nu_{\mathrm{P}-\mathrm{O}-\mathrm{C}}\right)$, indicating that

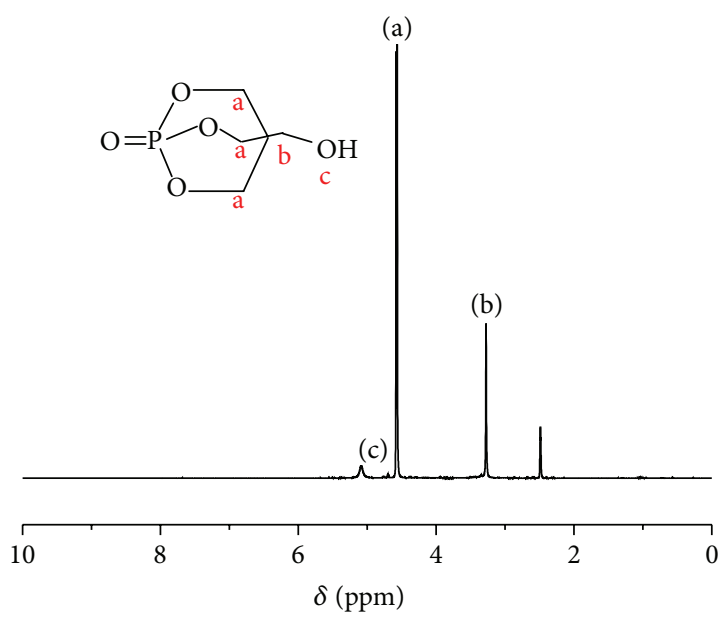

FIgURE 2: ${ }^{1} \mathrm{H}$-NMR spectrum of PEPA.

TABLE 1: The experimental and theoretical elemental analysis results of PEPA.

\begin{tabular}{lcccc}
\hline Elements & $\mathrm{C}$ & $\mathrm{H}$ & $\mathrm{O}$ & $\mathrm{P}$ \\
\hline Theoretical content (wt\%) & 33.33 & 5.00 & 44.44 & 17.23 \\
Experimental content (wt\%) & 33.51 & 3.90 & 45.23 & 17.36 \\
\hline
\end{tabular}

$\mathrm{POCl}_{3}$ was completely reacted with PER via nucleophilic substitution reaction. In addition, the appearance of the characteristic peak of caged bicyclic phosphate $\left(870 \mathrm{~cm}^{-1}\right)$ further confirmed that PEPA was successfully synthesized [20].

The ${ }^{1} \mathrm{H}-\mathrm{NMR}$ spectrum of PEPA was shown in Figure 2. The peak at about $4.5 \mathrm{ppm}$ was assigned to the $-\mathrm{CH}_{2}-$ protons (a) of the caged bicyclic ring. The peak at $3.2 \mathrm{ppm}$ was attributed to the $-\mathrm{CH}_{2}-$ protons (b) adjacent to the caged ring. The peak at about $5.1 \mathrm{ppm}$ was assigned to the $-\mathrm{OH}(\mathrm{c})$.

To further confirm the chemical structure of PEPA, the contents of $\mathrm{C}, \mathrm{H}$, and $\mathrm{O}$ were measured by an elemental analyzer (EA), and $\mathrm{P}$ was tested by an inductively coupled plasma-atomic emission spectrometer (ICP-AES). Table 1 presents the EA and ICP-AES data of PEPA. The content of $\mathrm{C}, \mathrm{H}, \mathrm{O}$, and $\mathrm{P}$ was $33.51 \mathrm{wt} \%, 3.90 \mathrm{wt} \%, 45.23 \mathrm{wt} \%$, and $17.36 \mathrm{wt} \%$, which were approximately in accordance with their theoretical content, respectively. Based on the above analysis, it was confirmed that PEPA had been synthesized successfully.

3.2. LOI and UL-94 Analysis. Table 2 lists the effect of MPP and PEPA content on the LOI and UL-94 test results of PP. It could be seen that the PP/MPP mixture showed low flame retardancy when MPP was used alone. The LOI value of PP-1 was only $23.0 \%$, and the UL-94 test classed no rating. This was mainly due to the lack of charring agent. MPP could not form an intumescent char layer on the surface of PP to prevent the substrate from burning. When employing some PEPA to replace part of MPP, the flame retardancy of the PP mixture was remarkably enhanced. With the increase of PEPA, the LOI value of the mixture increased first and then decreased. 
TABLE 2: Effect of MPP and PEPA content on the LOI and UL-94 test results of $\mathrm{PP}$.

\begin{tabular}{|c|c|c|c|c|c|}
\hline \multirow{2}{*}{ Samples } & \multicolumn{3}{|c|}{ Composition (wt\%) } & \multirow{2}{*}{ LOI (\%) } & \multirow{2}{*}{ UL-94 } \\
\hline & $\mathrm{PP}$ & MPP & PEPA & & \\
\hline PP & 100.0 & 0 & 0 & 17.5 & NR \\
\hline PP-1 & 80.0 & 20.0 & 0 & 23.0 & NR \\
\hline PP-2 & 80.0 & 0 & 20.0 & 24.0 & NR \\
\hline PP-3 & 80.0 & 15.0 & 5.0 & 26.5 & NR \\
\hline PP-4 & 80.0 & 13.3 & 6.7 & 28.0 & $\mathrm{~V}-1$ \\
\hline PP-5 & 80.0 & 10.0 & 10.0 & 30.0 & $\mathrm{~V}-1$ \\
\hline PP-6 & 80.0 & 6.7 & 13.3 & 33.0 & $\mathrm{~V}-0$ \\
\hline PP-7 & 80.0 & 5.0 & 15.0 & 31.0 & $\mathrm{~V}-1$ \\
\hline
\end{tabular}

TABLE 3: Characteristic parameters of the cone calorimetric test for $\mathrm{PP}$ and flame retardant PP.

\begin{tabular}{lccccc}
\hline Samples & $\begin{array}{c}\text { PHRR } \\
\left(\mathrm{kW} / \mathrm{m}^{2}\right)\end{array}$ & $\begin{array}{c}\text { AV-HRR } \\
\left(\mathrm{kW} / \mathrm{m}^{2}\right)\end{array}$ & $\begin{array}{c}\text { THR } \\
\left(\mathrm{MJ} / \mathrm{m}^{2}\right)\end{array}$ & $\begin{array}{c}\text { AV-MLR } \\
\left(\mathrm{g} / \mathrm{s} \cdot \mathrm{m}^{2}\right)\end{array}$ & $\begin{array}{c}\text { Residue at 700 s } \\
(\mathrm{wt} \%)\end{array}$ \\
\hline PP & 1128.7 & 343.8 & 149.5 & 0.087 & 0 \\
PP-1 & 446.5 & 229.3 & 144.5 & 0.055 & 8.3 \\
PP-2 & 775.0 & 156.5 & 130.9 & 0.062 & 9.8 \\
PP-6 & 244.4 & 208.9 & 133.6 & 0.036 & 23.8 \\
\hline
\end{tabular}

When the mass ratio of MPP to PEPA was $1: 2$, the LOI value of PP- 6 reached $33.0 \%$ and the UL-94 test classed a V- 0 rating, indicating that PEPA showed a good synergistic effect with MPP in flame retardant PP. This could be explained by the fact that, when being burned, PEPA could interact with MPP and formed an intumescent multicellular char, acting as a barrier which slowed down the heat and oxygen transfer, and thus prevented the polymer from burning. When the content of PEPA was not enough, MPP/PEPA formed a thin and weak intumescent char on the polymer because of the lack of charring source. On the contrary, when PEPA was excessive, there was not enough acid source to catalyze PEPA to form high quality intumescent char. When the mass ratio of MPP to PEPA was $1: 2$, the ratio of acid source, charring agent, and blowing agent was appropriate, and a high quality intumescent char layer was formed and covered on the surface of the polymer and thus effectively enhanced flame retardancy of PP.

3.3. Cone Calorimetric Analysis. The cone calorimetric test (CCT) is wildly used to evaluate the combustion behavior of materials. Some important combustion parameters can be obtained from the test, including heat release rate (HRR), total heat release (THR), and mass lose rate (MLR) [21, 22]. The combustion performance and the characteristic data of CCT for flame retardant PP are presented in Figure 3 and Table 3.

Figure 3 shows the HRR and THR curves of PP and flame retardant PP. It was observed that the pure PP burnt out within $370 \mathrm{~s}$ after ignition. HRR reached a sharp peak with a peak heat release rate (PHRR) of $1128.7 \mathrm{~kW} / \mathrm{m}^{2}$, and the average heat release rate (AV-HRR) was $343.8 \mathrm{~kW} / \mathrm{m}^{2}$. For PP-1 and PP-2, the PHRR were $446.5 \mathrm{~kW} / \mathrm{m}^{2}$ and
TABLE 4: TGA characteristic parameters of PP and the flame retardant $\mathrm{PP}$ under air atmosphere.

\begin{tabular}{lcccc}
\hline Samples & $\begin{array}{c}T_{i} \\
\left({ }^{\circ} \mathrm{C}\right)\end{array}$ & $\begin{array}{c}T_{\max } \\
\left({ }^{\circ} \mathrm{C}\right)\end{array}$ & $\begin{array}{c}R_{\max } \\
(\mathrm{wt} \% / \mathrm{min})\end{array}$ & $\begin{array}{c}\text { Residue at } 700^{\circ} \mathrm{C} \\
(\mathrm{wt} \%)\end{array}$ \\
\hline PP & 269 & 337 & 28.1 & 0 \\
PP-1 & 278 & 346 & 23.5 & 8.9 \\
PP-2 & 292 & 341 & 21.6 & 9.2 \\
PP-6 & 287 & 346 & 19.6 & 9.6 \\
\hline
\end{tabular}

$775.0 \mathrm{~kW} / \mathrm{m}^{2}$, and the AV-HHR was $229.3 \mathrm{~kW} / \mathrm{m}^{2}$ and $249.2 \mathrm{~kW} / \mathrm{m}^{2}$, respectively. For PP-6, the PHRR and AV-HHR were $244.4 \mathrm{~kW} / \mathrm{m}^{2}$ and $156.5 \mathrm{~kW} / \mathrm{m}^{2}$, which were $78.3 \%$ and 54.5\% lower than those of the pure PP, respectively. These results indicated that the synergistic effect between MPP and PEPA could enhance the flame retardancy of PP, which was in accordance with the LOI and UL-94 test results. Compared with the pure PP, it was obvious that the burning time of PP6 was prolonged remarkably. Moreover, it could be seen from Figure 3(b) that, after combustion for $300 \mathrm{~s}$, the THR of the PP resin reached $144 \mathrm{MJ} / \mathrm{m}^{2}$, while the value was only $59 \mathrm{MJ} / \mathrm{m}^{2}$ for PP- 6 at the same time. The reason might be related to the formation of continuous and compact intumescent char, which acted as barrier to prevent combustible gas from feeding the flame and protect the underlying matrix effectively from further burning [23].

As also listed in Table 3, the average mass loss rate (AV-MLR) for PP, PP-1, PP-2, and PP-6 were 0.087, 0.055, 0.062 , and $0.036 \mathrm{~g} / \mathrm{s} \cdot \mathrm{m}^{2}$, respectively. At the end of burning, the residues of PP-1, PP-2, and PP- 6 at $700 \mathrm{~s}$ were $8.3 \mathrm{wt} \%$, $9.8 \mathrm{wt} \%$, and $23.8 \mathrm{wt} \%$, respectively, while there was almost no char left for the pure PP. The residue of PP- 6 was more than those of PP-1 and PP-2, which further confirmed that the synergistic effect between MPP and PEPA could significantly improve the char-forming capability of PP.

3.4. Thermal Behavior. The interaction between MPP and PEPA could be revealed by the experimental and calculated TGA curves. Figure 4 shows the TGA and DTG curves of MPP, PEPA, and MPP/PEPA under air atmosphere. The experimental curve was directly obtained from the thermogravimeter, while the calculated curve was the sum of the normalized weight loss of MPP and PEPA. The distinct difference between the experimental and calculated results indicated a strong interaction between MPP and PEPA. When the temperature was $250^{\circ} \mathrm{C}$, the mixture began to lose mass due to the esterification between MPP and PEPA, which eliminated some kinds of small molecule; thus the experimental curve had lower thermostability than the calculated one. As the temperature increased, the experimental curve exhibited much higher thermostability, which indicated that MPP could react with PEPA and form a more thermostable char layer. With the further increase of temperature, the mass loss rate of MPP/PEPA reached a maximum at about $430^{\circ} \mathrm{C}$. This may be explained by the decomposition of MPP and PEPA, which would produce large amounts of $\mathrm{NH}_{3}$ and some phosphorus-containing compounds at high 


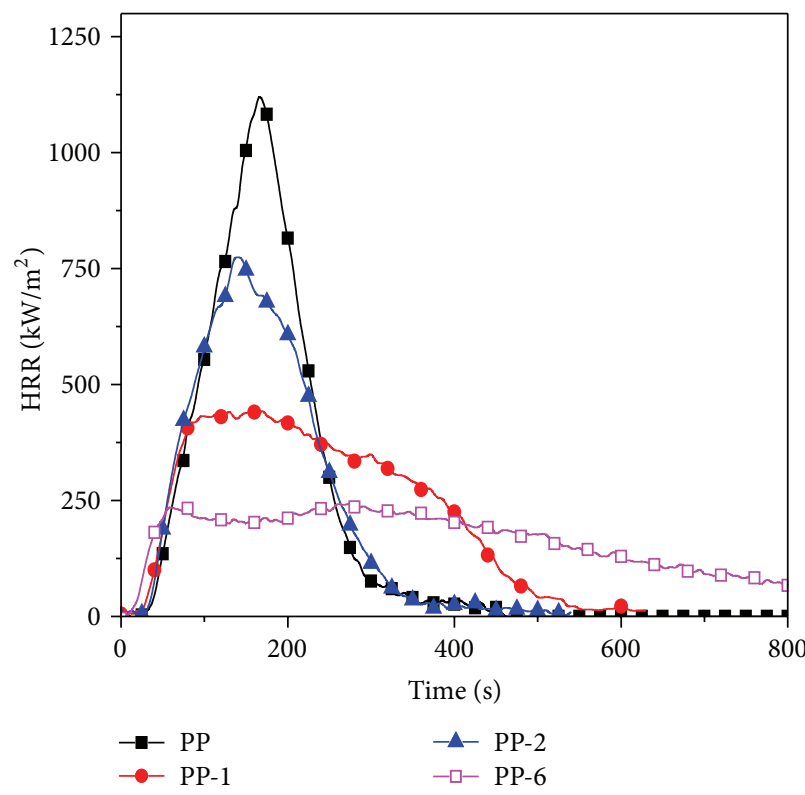

(a)

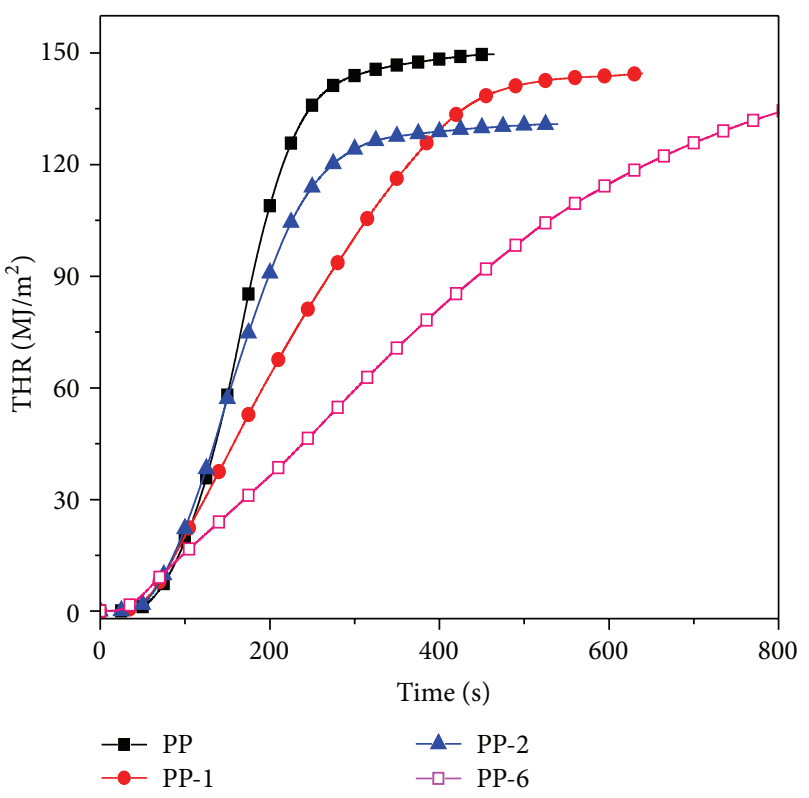

(b)

FIgURe 3: (a) HRR and (b) THR curves of PP and flame retardant PP at a flux of $35 \mathrm{~kW} / \mathrm{m}^{2}$.

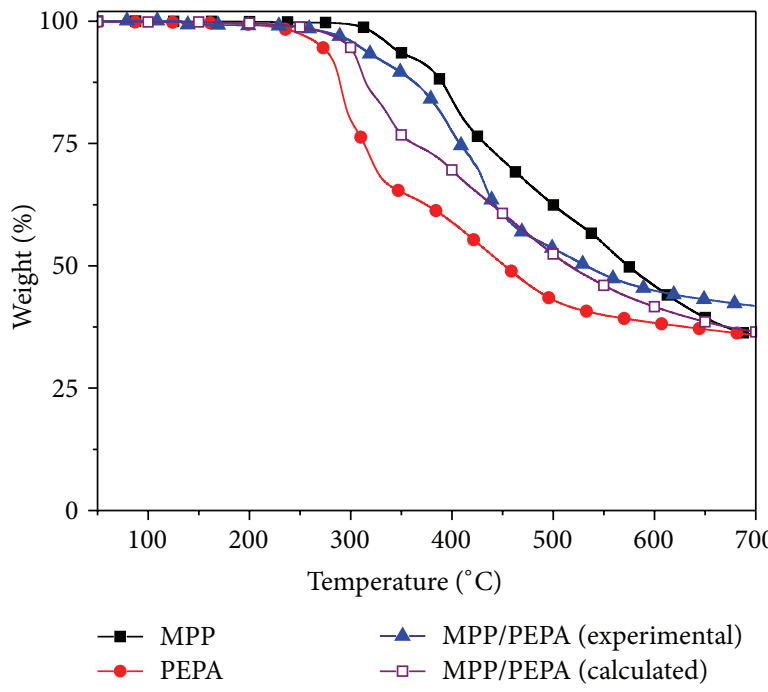

(a)

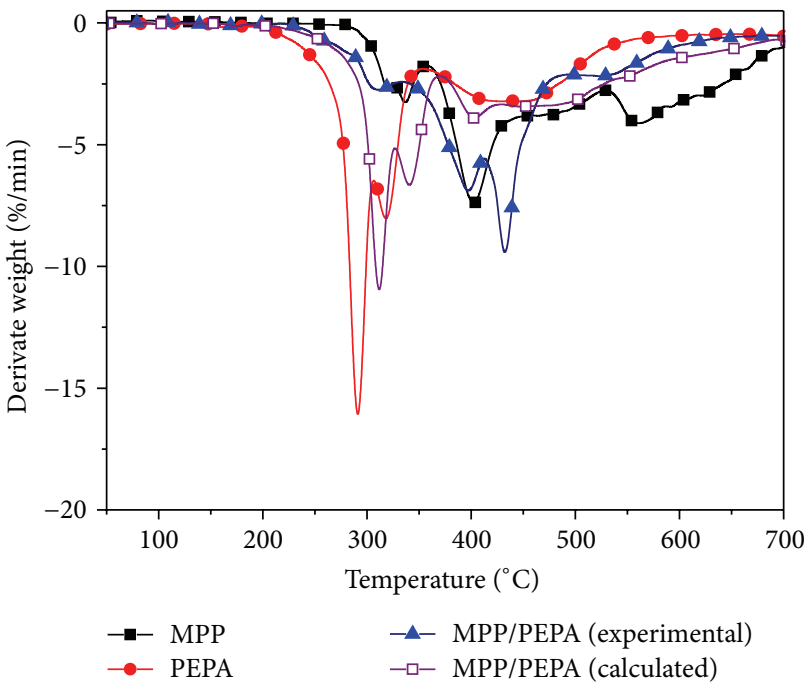

(b)

FIgURE 4: (a) TGA and (b) DTG curves of MPP, PEPA, and MPP/PEPA under air atmosphere. Note: the mass ratio of MPP to PEPA was 1:2.

temperature. Above $600^{\circ} \mathrm{C}$, the experimental curve almost unchanged, indicating that the intumescent char formed by MPP/PEPA was thermostable. The experimental residue of $\mathrm{MPP} / \mathrm{PEPA}$ at $700^{\circ} \mathrm{C}$ was $41.8 \mathrm{wt} \%$, whereas it was only $36.5 \mathrm{wt} \%$ based on the calculation, which also confirmed that there was an outstanding char-forming capability of MPP/PEPA.

Figure 5 shows the FTIR spectra of MPP/PEPA after heat treatment at different temperature. As could be seen, the relative intensities of the characteristic bands for the MPP/PEPA mixture were almost unchanged below $250^{\circ} \mathrm{C}$.
Above $250^{\circ} \mathrm{C}$, the decrease of intensity of the broad band around $3200 \sim 3500 \mathrm{~cm}^{-1}\left(v_{\mathrm{O}-\mathrm{H}}\right)$ and the increase of intensity of the $1075 \mathrm{~cm}^{-1}\left(v_{\mathrm{P}-\mathrm{O}-\mathrm{C}}\right)$ peak were caused by the dehydration between MPP and PEPA. With the increase of the temperature, the absorption of $863 \mathrm{~cm}^{-1}$ (the caged bicyclic phosphate) and $1075 \mathrm{~cm}^{-1}\left(v_{\mathrm{P}-\mathrm{O}-\mathrm{C}}\right)$ was significantly decreased $[10,15]$, which was attributed to the degradation of phosphate esters to form thermostable pyrophosphate. Simultaneously, the phosphorus-containing compound radicals including pyrophosphate radicals and phosphate ester radicals were generated by the decomposition of PEPA, which 


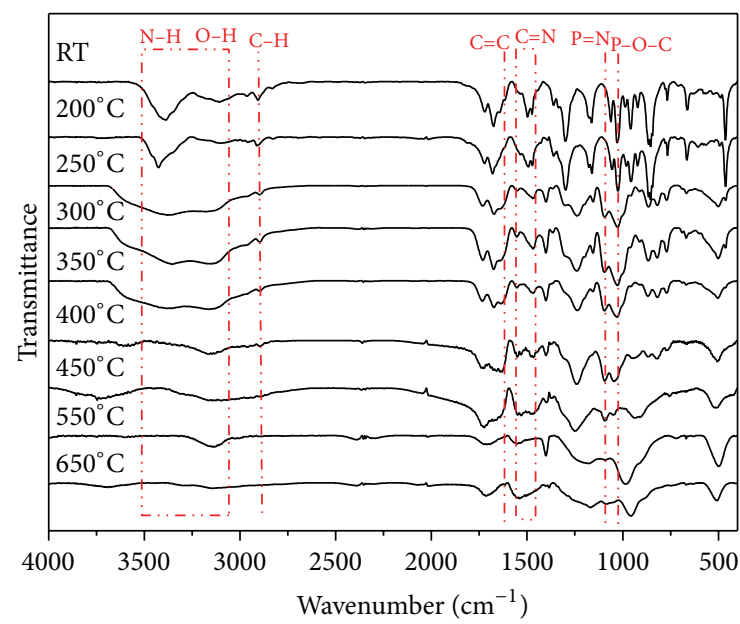

FIGURE 5: FTIR spectra of MPP/PEPA treated at different temperatures for $15 \mathrm{~min}$. Note: the mass ratio of MPP to PEPA was $1: 2$.

played an important role in the interruption of free radicals chain reaction [3]. Meanwhile, the increased band at about $1620 \mathrm{~cm}^{-1}$ was ascribed to $\mathrm{C}=\mathrm{C}$ structure $[24,25]$, which was also produced by PEPA and could promote the formation of thermostable residue [19]. When the temperature reached up to $400^{\circ} \mathrm{C}$, there was a new peak around $1100 \mathrm{~cm}^{-1}$ appearing, which corresponded to $\mathrm{P}-\mathrm{N}$ absorption [26], indicating that the phosphorus-containing compounds could further crosslink with the triazine oligomer produced by MPP [3, 27]. With the further increase of pyrolysis temperature, the intensities of the bands at $3200-3500 \mathrm{~cm}^{-1}\left(v_{\mathrm{N}-\mathrm{H}}\right.$ and $\left.v_{\mathrm{O}-\mathrm{H}}\right)$ decreased gradually and nearly disappeared at $550^{\circ} \mathrm{C}$ to $650^{\circ} \mathrm{C}$. However, the bands at $1075 \mathrm{~cm}^{-1}\left(v_{\mathrm{P}-\mathrm{O}-\mathrm{C}}\right), 1100 \mathrm{~cm}^{-1}$ $\left(v_{\mathrm{P}-\mathrm{N}}\right)$, and $1485 \mathrm{~cm}^{-1}\left(v_{\mathrm{C}=\mathrm{N}}\right)$ were almost invariable. These results suggested that MPP had reacted with PEPA and formed a cross-linked structure, containing $\mathrm{P}-\mathrm{O}-\mathrm{C}, \mathrm{P}-\mathrm{N}$ and $\mathrm{C}=\mathrm{N}$ bonds and acting as a thermostable graphite-like char [14].

In order to further investigate the interaction between MPP and PEPA, TG-FTIR was used to analyze the pyrolysis products and gas products evolved during the thermal degradation. Figure 6 presents the FTIR spectra of pyrolysis gases of the MPP/PEPA mixture at various temperatures. It could be seen that there was almost no infrared signal below $250^{\circ} \mathrm{C}$. With the increase of temperature, there was a weak signal which appeared belonging to $\mathrm{H}_{2} \mathrm{O}$ at $1645 \mathrm{~cm}^{-1}$ in $250^{\circ} \mathrm{C}$, which could be assigned to the esterification and dehydration of MPP and PEPA. When the temperature was raised to $350^{\circ} \mathrm{C}$, the bands of $\mathrm{P}-\mathrm{O}-\mathrm{P}\left(845 \mathrm{~cm}^{-1}\right)$ and $\mathrm{P}-\mathrm{O}-\mathrm{C}$ $\left(1075 \mathrm{~cm}^{-1}\right)$ appeared, which were attributed to the pyrophosphate fragment and phosphate ester fragment, respectively. Simultaneously, the appearance of $\mathrm{NH}_{3}\left(950 \mathrm{~cm}^{-1}\right)$ indicated that MPP started to decompose to release large amount of $\mathrm{NH}_{3}$ and generated the triazine oligomer $[3,27]$. These phenomena were coincident with the TGA and FTIR spectra of MPP/PEPA results. With the further increase of temperature, the band of carbon oxide and $\mathrm{H}_{2} \mathrm{O}$ became stronger and diluted the oxidizing and combustible gas phases because of

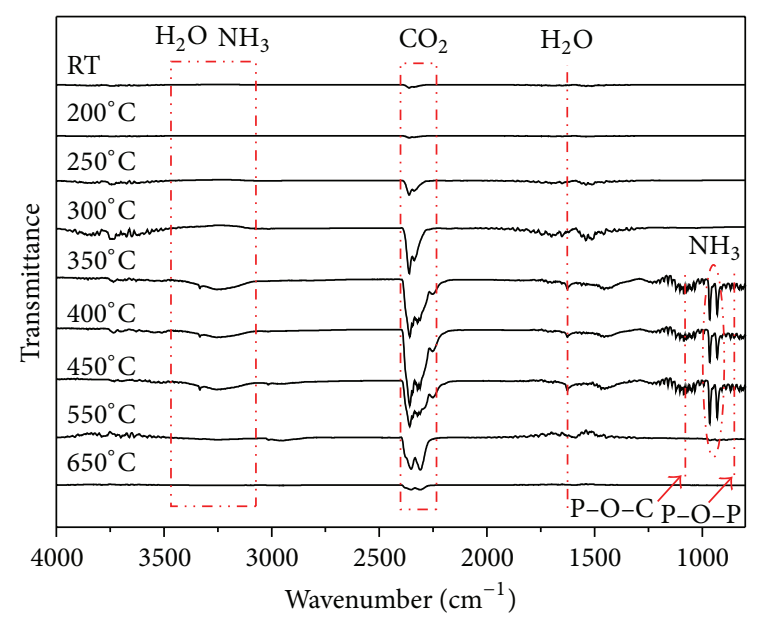

FIGURE 6: FTIR spectra of pyrolysis gases of the MPP/PEPA mixture at various temperatures. Note: the mass ratio of MPP to PEPA was $1: 2$.

the further degradation of the unstable partial char of the residue. As the temperature reached up to $650^{\circ} \mathrm{C}$, all peaks nearly disappeared, meaning that the process of decomposition had finished and a thermostable char was formed.

Figure 7 presents the TGA and DTG curves of PP and the flame retardant PP under air atmosphere, and the detailed results are listed in Table 4 . It could be seen that pure PP began to decompose at $269^{\circ} \mathrm{C}$ and the temperature at maximum mass loss rate $\left(T_{\max }\right)$ was $337^{\circ} \mathrm{C}$ with almost no residue left at $470^{\circ} \mathrm{C}$. As expected, the incorporation of $20 \mathrm{wt} \%$ PEPA into PP resulted in the increase of $T_{i}$ and $T_{\max }$, which were $23^{\circ} \mathrm{C}$ and $4^{\circ} \mathrm{C}$ higher than those of $\mathrm{PP}$, respectively. This could be explained by the fact that the phosphoruscontaining compounds (mainly the $\mathrm{P}-\mathrm{O}$ - radicals) which decomposed by PEPA could quench the free radicals like $\mathrm{H} \bullet$ and $\mathrm{OH} \bullet$ when PP composite was heating and improved the thermostability of PP $[3,28]$. When combined with MPP, the $T_{i}$ of PP- 6 declined $5^{\circ} \mathrm{C}$ compared with PP/PEPA composite. This was because of the esterification reaction between MPP and PEPA. However, the residue of PP-6 at $700^{\circ} \mathrm{C}$ was $9.6 \mathrm{wt} \%$, which was higher than that of PP- 1 and PP-2, indicating that the synergistic effect between MPP andPEPA could improve the char-forming property of PP.

Figure 8 shows the 3D TG-FTIR spectra of pyrolysis gases of (a) PP and (b) PP-6 during the thermal degradation. Figure 9 presents the evolution curves of hydrocarbons, which are the main gaseous pyrolysis products of $\mathrm{PP}$ and PP6. Pure PP began to release some hydrocarbons $\left(2961 \mathrm{~cm}^{-1}\right)$ at $331^{\circ} \mathrm{C}$. For PP-6, the initial hydrocarbons gases release occurred at $355^{\circ} \mathrm{C}$, which was $24^{\circ} \mathrm{C}$ higher than that of the pure $\mathrm{PP}$, indicating that the phosphorus-containing compounds could trap the free radicals and enhance the thermostability of PP $[3,28]$. With the increase of temperature, the evolution of hydrocarbons for pure PP- 6 reached a maximum at $551^{\circ} \mathrm{C}$, which was $73^{\circ} \mathrm{C}$ higher than that of the pure PP $\left(478^{\circ} \mathrm{C}\right)$. What is more, the intensity of the hydrocarbons released by PP- 6 was much lower than that of pure PP. This was due to the fact that thermostable char 


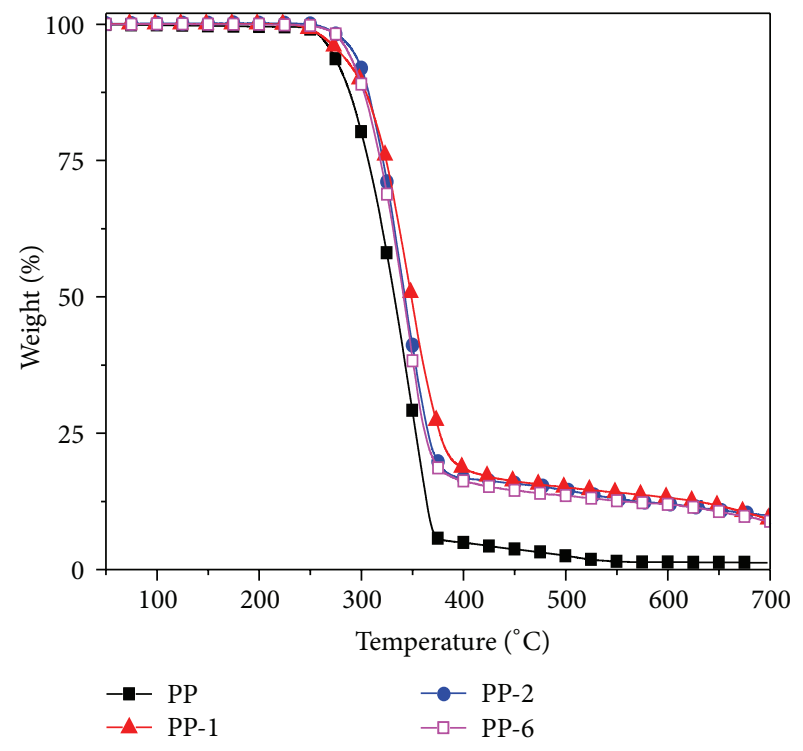

(a)

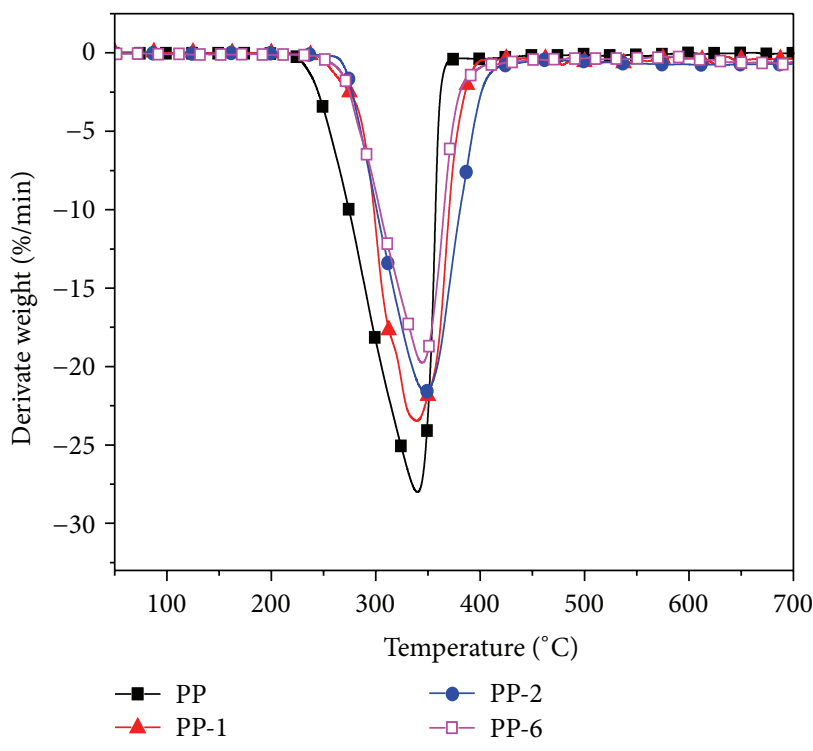

(b)

Figure 7: (a) TGA and (b) DTG curves of PP and the flame retardant PP under air atmosphere.

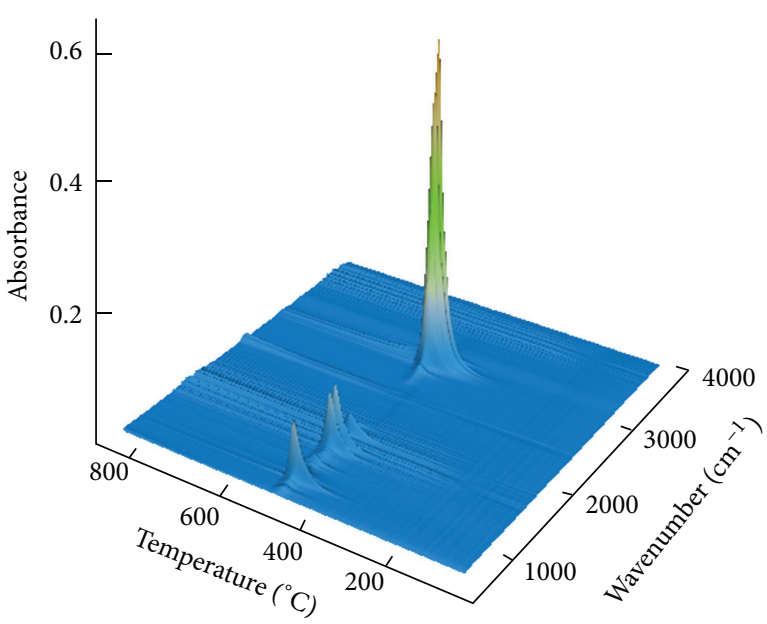

(a)

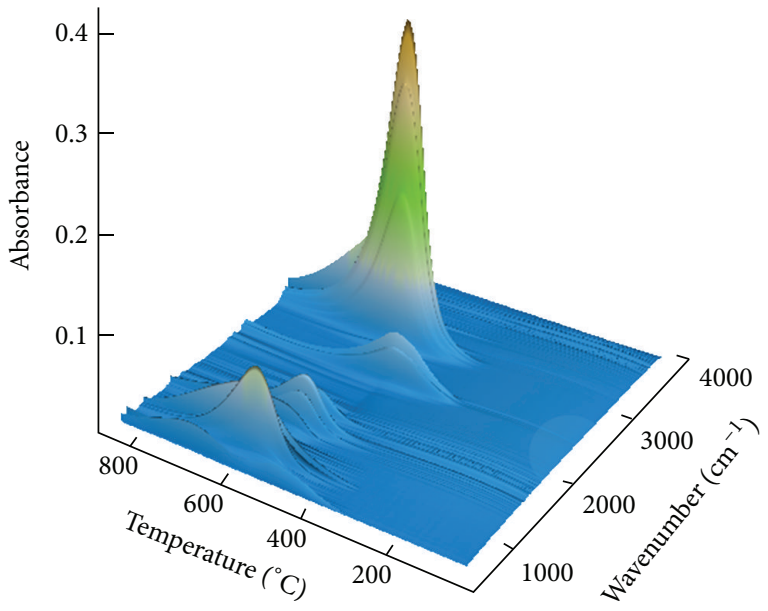

(b)

FIGURE 8: 3D TG-FTIR spectra of pyrolysis gases of (a) PP and (b) PP-6 during the thermal degradation.

layer formed by MPP/PEPA could effectively slow down the combustible gas and heat transfer and thus prevented the inner mixture from further decomposition.

3.5. Morphology and SEM-EDXS Analysis of the Residue. Figure 10 displays the digital photographs of PP and the flame retardant PP after the cone calorimetric test. It could be clearly seen that PP was burnt completely with no residue left (Figure 10(a)), while there was some intumescent char left for all of the flame retardant PP. However, the char layers of PP-1 and PP-2 were thin and broken (Figures 10(b) and $10(\mathrm{c})$ ), which could not effectively slow down either the combustible gas or heat transfer, resulting in the poor flame retardancy of the mixture [29]. When MPP was combined with PEPA to flame-retardant PP, a swollen and compact char layer was formed by MPP/PEPA covered on the substrate (Figure 10(d)), which could effectively block the transmission of oxygen, combustible gases, and heat and thus prevented the matrix from burning [30]. The micromorphology and composition of the outer char layer of PP- 6 were also observed by the scanning electron microscopy-energy dispersive $\mathrm{X}$ ray spectrometry (SEM-EDXS). As shown in Figure 11, the surface of intumescent char layer for PP-6 was compact and dense. The composition of the char layer included $36.8 \mathrm{wt} \%$ carbon (C), $10.2 \mathrm{wt} \%$ nitrogen $(\mathrm{N}), 43.1 \mathrm{wt} \%$ oxygen $(\mathrm{O})$, and 9.9 wt $\%$ phosphorus $(\mathrm{P})$. The high $\mathrm{C}, \mathrm{N}$, and $\mathrm{P}$ contents of the char layer indicate that $\mathrm{C}$ atoms probably were cross-linked with $\mathrm{N}$ and $\mathrm{P}$ atoms, which could effectively promote the matrix to form a thermostable char [31]. 


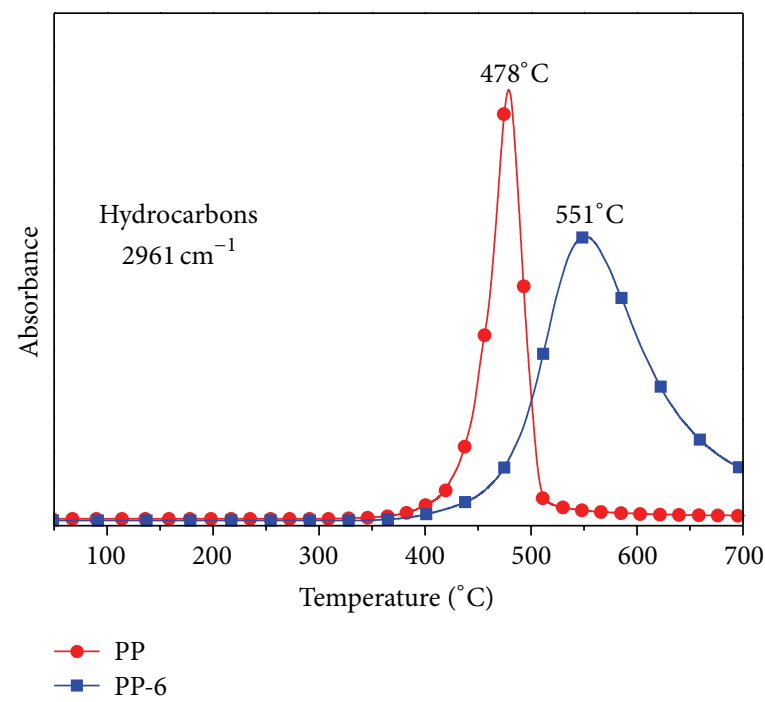

FIGURE 9: FTIR absorbance versus temperature curves of hydrocarbons evolved from PP and PP-6.
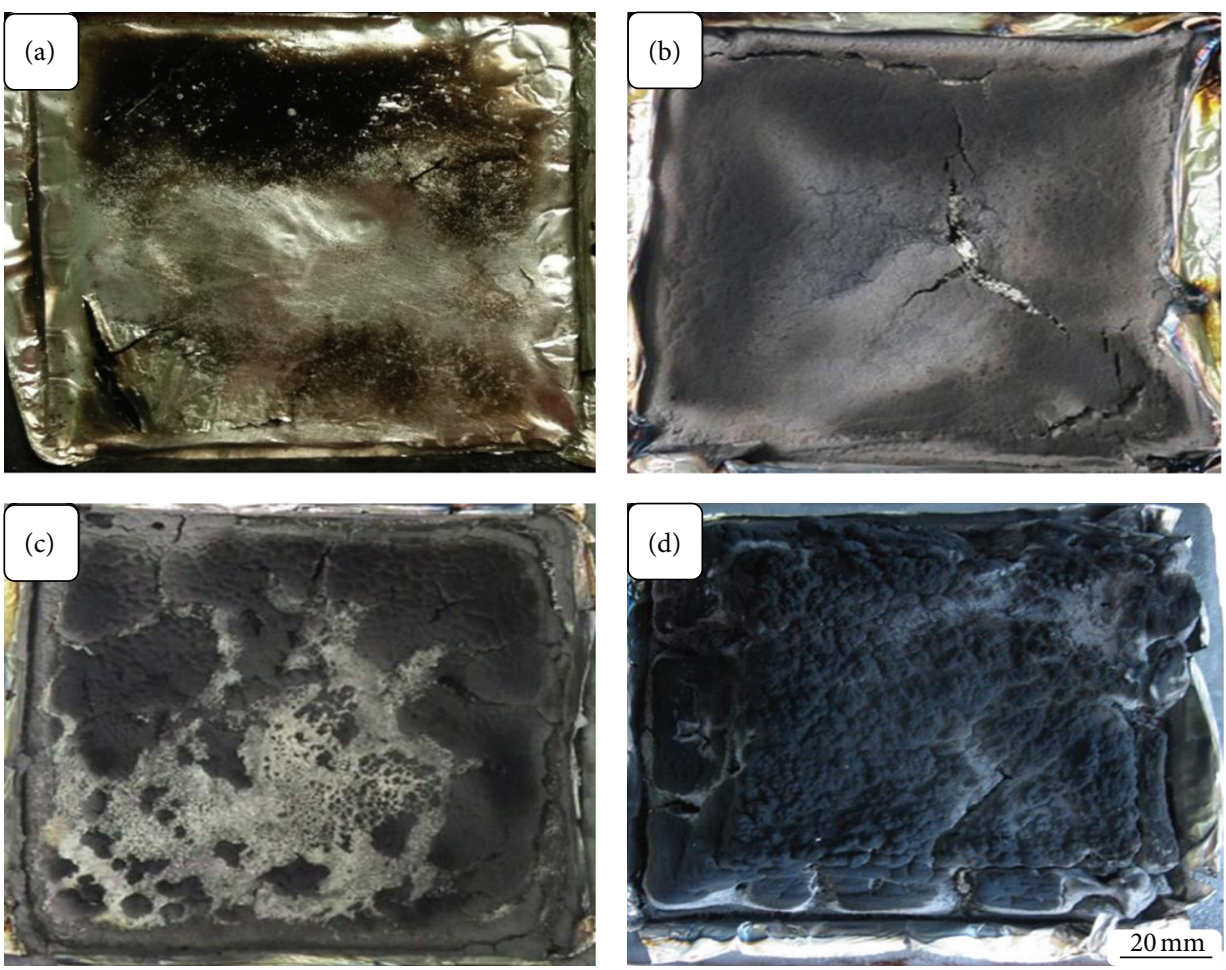

Figure 10: Digital photographs of PP and the flame retardant PP after the cone calorimetric test: (a) PP, (b) PP-1, (c) PP-2, and (d) PP-6.

3.6. Possible Flame-Retardant and Thermal Degradation Mechanism. Based on the results above, the possible flame-retardant and thermal degradation mechanism of $\mathrm{MPP} / \mathrm{PEPA}$ for PP is shown in Figure 12 . Above $250^{\circ} \mathrm{C}$, the formation of $\mathrm{P}-\mathrm{O}-\mathrm{C}$ bond occurred from the esterification and dehydration reaction between MPP and PEPA. As the temperature increased, the cage structure of PEPA was destroyed to form phosphorus-containing compound radicals and $\mathrm{C}=\mathrm{C}$ structure compound. Simultaneously, MPP was decomposed to form the triazine oligomer. Those radicals could quench the free radicals (such as $-\mathrm{CO} \bullet$ and $-\mathrm{COO} \bullet$ ) produced by the degradation of PP and promoted the thermostability of $\mathrm{PP}$. Then the $\mathrm{C}=\mathrm{C}$ structure and phosphorus-containing compounds began to aromatize with the triazine oligomers to form a precursor char layer. After that, some incombustible gases like $\mathrm{NH}_{3}, \mathrm{H}_{2} \mathrm{O}$, and $\mathrm{CO}_{2}$ were released to take away part of the heat and swell the precursor layer. With the increase of temperature, the further cross-linked reaction of MPP/PEPA formed P-N bonds and improved the formation of an intumescent and compact char 


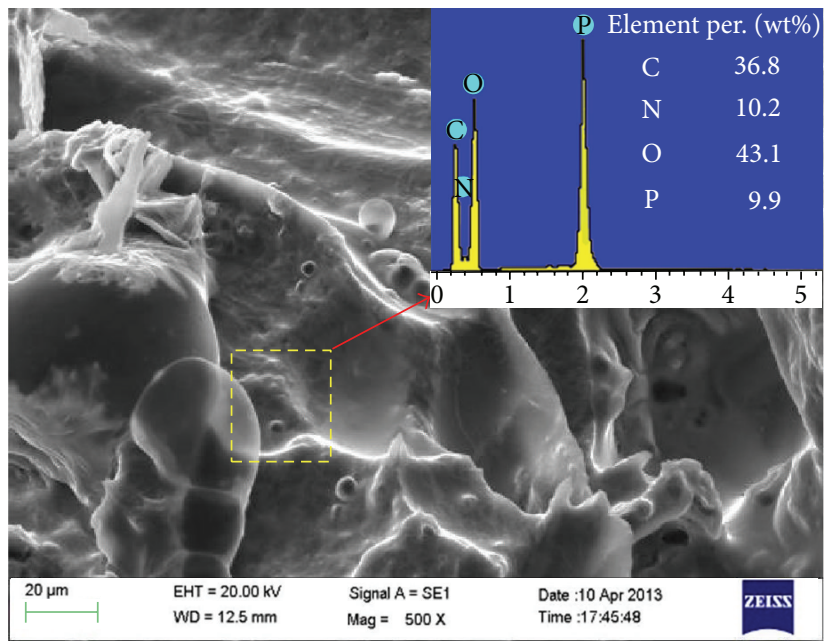

FIGURE 11: SEM-EDXS image of the outer char surface for the PP-6 after the cone calorimetric test.

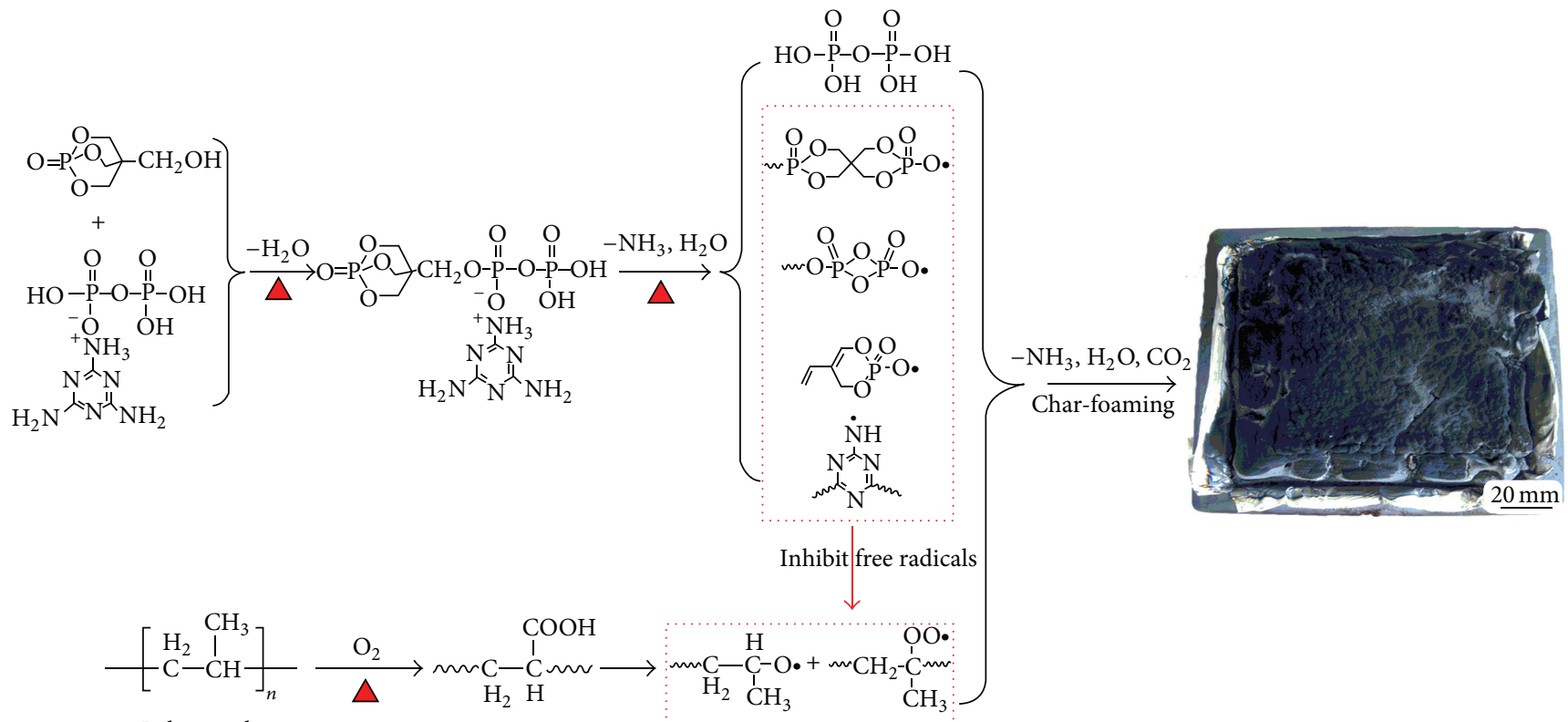

Polypropylene

FIGURE 12: Possible flame-retardant and thermal degradation mechanism of MPP/PEPA for PP.

layer, which could slow down the heat and combustible gases transfer, and thus protected the polymer from degrading and burning.

\section{Conclusions}

An efficient caged phosphate charring agent named PEPA was synthesized successfully, and it showed an outstanding synergistic effect with MPP in flame retardant PP. When the content of PEPA was $13.3 \mathrm{wt} \%$ and MPP was $6.7 \mathrm{wt} \%$, the LOI value of the PP/MPP/PEPA mixture was 33.0\%, and the UL-94 test reached a V-0 rating. Meanwhile, the peak heat release rate (PHRR), total heat release (THR), and average mass lose rate (AV-MLR) were also significantly reduced. The result of TGA, TG-FTIR, and SEM-EDXS revealed that, when being burned, MPP/PEPA could generate the phosphorus-containing compound radicals and the triazine oligomer radicals which captured the free radicals of PP chain scission, and thus inhibited the degradation and combustion of the polymer. Afterwards, the cyclization between the $\mathrm{C}=\mathrm{C}$ structure, phosphorus-containing compounds, and the triazine oligomers could form a cross-linked precursor char containing $\mathrm{P}-\mathrm{O}-\mathrm{C}, \mathrm{P}-\mathrm{N}$, and $\mathrm{C}=\mathrm{N}$ bonds. Finally, a compact, continuous, and thermostable char layer was formed, which could effectively separate the heat, oxygen, and combustible gas from transferring, and thus prevented the substrate from degrading and burning. 


\section{Conflict of Interests}

The authors declare that there is no conflict of interests regarding the publication of this paper.

\section{Acknowledgments}

The authors gratefully acknowledge the financial supports by the National Natural Science Foundation of China (51403067), the Guangdong Natural Science Foundation (S2013040015249), the China Postdoctoral Science Foundation (2014M560660), the Fundamental Research Funds for the Central Universities (2015ZM014), National Training Program of Innovation and Entrepreneurship for Undergraduates (201410561036), and Fundamental Research Funds for the Central Universities Undergraduate Independent Research Projects (10561201449).

\section{References}

[1] J. Guo, M. He, Q. Li, J. Yu, and S. Qin, "Synergistic effect of organo-montmorillonite on intumescent flame retardant ethylene-octene copolymer," Journal of Applied Polymer Science, vol. 129, no. 4, pp. 2063-2069, 2013.

[2] G. X. Li, S. K. Cao, S. J. Zheng, W. J. Wang, Y. X. Cao, and J. X. Wang, "Crystallization, melting behavior, and crystal structure of reactive, intumescent, flame-retardant polypropylene," Journal of Applied Polymer Science, vol. 132, no. 5, 2015.

[3] X. J. Lai, S. Tang, H. Q. Li, and X. R. Zeng, "Flame-retardant mechanism of a novel polymeric intumescent flame retardant containing caged bicyclic phosphate for polypropylene," Polymer Degradation and Stability, vol. 113, pp. 22-31, 2015.

[4] C. A. Wilkie and A. B. Morgan, Fire Retardancy of Polymeric Materials, CRC Press, London, UK, 2nd edition, 2009.

[5] S. Bourbigot, M. le Bras, S. Duquesne, and M. Rochery, "Recent advances for intumescent polymers," Macromolecular Materials and Engineering, vol. 289, no. 6, pp. 499-511, 2004.

[6] S. Bourbigot, M. L. Bras, and R. Delobel, "Carbonization mechanisms resulting from intumescence association with the ammonium polyphosphate-pentaerythritol fire retardant system," Carbon, vol. 31, no. 8, pp. 1219-1230, 1993.

[7] G. Camino, L. Costa, and M. P. L. di Cortemiglia, "Overview of fire retardant mechanisms," Polymer Degradation and Stability, vol. 33, no. 2, pp. 131-154, 1991.

[8] G. Camino, N. Grassie, and I. C. McNeill, "Influence of the fire retardant, ammonium polyphosphate, on the thermal degradation of poly(methyl methacrylate)," Journal of Polymer Science Part A-Polymer Chemistry, vol. 16, no. 1, pp. 95-106, 1978.

[9] C. M. Jiao, J. Zhang, and F. Zhang, "Combustion behavior of intumescent flame retardant polypropylene composites," Journal of Fire Sciences, vol. 26, no. 5, pp. 455-469, 2008.

[10] C. M. Jiao and X. L. Chen, "Flammability and thermal degradation of intumescent flame-retardant polypropylene composites," Polymer Engineering \& Science, vol. 50, no. 4, pp. 767-772, 2010.

[11] Z. Hu, G.-P. Lin, L. Chen, and Y.-Z. Wang, "Flame retardation of glass-fiber-reinforced polyamide 6 by combination of aluminum phenylphosphinate with melamine pyrophosphate," Polymers for Advanced Technologies, vol. 22, no. 7, pp. 1166-1173, 2011.
[12] K. Y. Fang, J. Li, C. H. Ke, Q. L. Zhu, J. Zhu, and Q. Yan, "Synergistic effect between a novel hyperbranched flame retardant and melamine pyrophosphate on the char forming of polyamide 6," Polymer-Plastics Technology and Engineering, vol. 49, no. 14, pp. 1489-1497, 2010.

[13] K. Y. Fang, J. Li, C. H. Ke et al., "Intumescent flame retardation of melamine-modified montmorillonite on polyamide 6: enhancement of condense phase and flame retardance," Polymer Engineering \& Science, vol. 51, no. 2, pp. 377-385, 2011.

[14] H.-Q. Peng, Q. Zhou, D.-Y. Wang, L. Chen, and Y.-Z. Wang, "A novel charring agent containing caged bicyclic phosphate and its application in intumescent flame retardant polypropylene systems," Journal of Industrial and Engineering Chemistry, vol. 14, no. 5, pp. 589-595, 2008.

[15] W. Z. Jiang, J. Hao, and Z. D. Han, "Study on the thermal degradation of mixtures of ammonium polyphosphate and a novel caged bicyclic phosphate and their flame retardant effect in polypropylene," Polymer Degradation and Stability, vol. 97, no. 4, pp. 632-637, 2012.

[16] X. F. Yang, N. L. Ge, L. Y. Hu, H. G. Gui, Z. G. Wang, and Y. S. Ding, "Synthesis of a novel ionic liquid containing phosphorus and its application in intumescent flame retardant polypropylene system," Polymers for Advanced Technologies, vol. 24, no. 6, pp. 568-575, 2013.

[17] C. Feng, Y. Zhang, D. Liang, S. Liu, Z. Chi, and J. Xu, "Flame retardancy and thermal degradation behaviors of polypropylene composites with novel intumescent flame retardant and manganese dioxide," Journal of Analytical and Applied Pyrolysis, vol. 104, pp. 59-67, 2013.

[18] D. J. Zhu, X. B. Li, Z. F. Zhou, F. M. Ren, and W. B. Xu, "Preparation and properties of intumescent flame retardant APP/MPR/PEPA and its application in ABS," China Plastics Industry, vol. 42, no. 3, pp. 107-110, 2014.

[19] A. I. Balabanovich, "Thermal decomposition study of intumescent additives: pentaerythritol phosphate and its blend with melamine phosphate," Thermochimica Acta, vol. 435, no. 2, pp. 188-196, 2005.

[20] B. Schartel and T. R. Hull, "Development of fire-retarded materials-interpretation of cone calorimeter data," Fire and Materials, vol. 31, no. 5, pp. 327-354, 2007.

[21] P. Zhang, L. Song, H. Lu, J. Wang, and Y. Hu, "The thermal property and flame retardant mechanism of intumescent flame retardant paraffin system with metal," Industrial \& Engineering Chemistry Research, vol. 49, no. 13, pp. 6003-6009, 2010.

[22] N. H. Huang, Z. J. Chen, J. Q. Wang, and P. Wei, “Synergistic effects of sepiolite on intumescent flame retardant polypropylene," Express Polymer Letters, vol. 4, no. 12, pp. 743-752, 2010.

[23] S. Zhou, L. Song, Z. Z. Wang, Y. Hu, and W. Xing, "Flame retardation and char formation mechanism of intumescent flame retarded polypropylene composites containing melamine phosphate and pentaerythritol phosphate," Polymer Degradation and Stability, vol. 93, no. 10, pp. 1799-1806, 2008.

[24] W. X. Huang, G. L. Baker, and M. L. Bruening, "Controlled synthesis of cross-linked ultrathin polymer films by using surfaceinitiated atom transfer radical polymerization," Angewandte Chemie International Edition, vol. 40, no. 8, pp. 1510-1512, 2001.

[25] D.-Y. Wang, Y. Liu, Y.-Z. Wang, C. P. Artiles, T. R. Hull, and D. Price, "Fire retardancy of a reactively extruded intumescent flame retardant polyethylene system enhanced by metal chelates," Polymer Degradation and Stability, vol. 92, no. 8, pp. 1592-1598, 2007. 
[26] G. X. Li, W. J. Wang, S. K. Cao, Y. X. Cao, and J. W. Wang, "Reactive, intumescent, halogen-free flame retardant for polypropylene," Journal of Applied Polymer Science, vol. 131, no. 7, Article ID 40054, 2014.

[27] X. Su, Y. Yi, J. Tao, H. Qi, and D. Li, "Synergistic effect between a novel triazine charring agent and ammonium polyphosphate on flame retardancy and thermal behavior of polypropylene," Polymer Degradation and Stability, vol. 105, no. 1, pp. 12-20, 2014.

[28] N. N. Tian, J. Gong, X. Wen, K. Yao, and T. Tang, "Synthesis and characterization of a novel organophosphorus oligomer and its application in improving flame retardancy of epoxy resin," RSC Advances, vol. 4, no. 34, pp. 17607-17614, 2014.

[29] X. J. Lai, X. R. Zeng, H. Q. Li, and H. L. Zhang, "Effect of polyborosiloxane on the flame retardancy and thermal degradation of intumescent flame retardant polypropylene," Journal of Macromolecular Science Part B: Physics, vol. 53, no. 4, pp. 721734, 2014.

[30] Y. Chen, Z. Jia, Y. Luo, D. Jia, and B. Li, "Environmentally friendly flame-retardant and its application in rigid polyurethane foam," International Journal of Polymer Science, vol. 2014, Article ID 263716, 7 pages, 2014.

[31] J. Chen, S. M. Liu, and J. Q. Zhao, "Synthesis, application and flame retardancy mechanism of a novel flame retardant containing silicon and caged bicyclic phosphate for polyamide 6," Polymer Degradation and Stability, vol. 96, no. 8, pp. 1508-1515, 2011. 

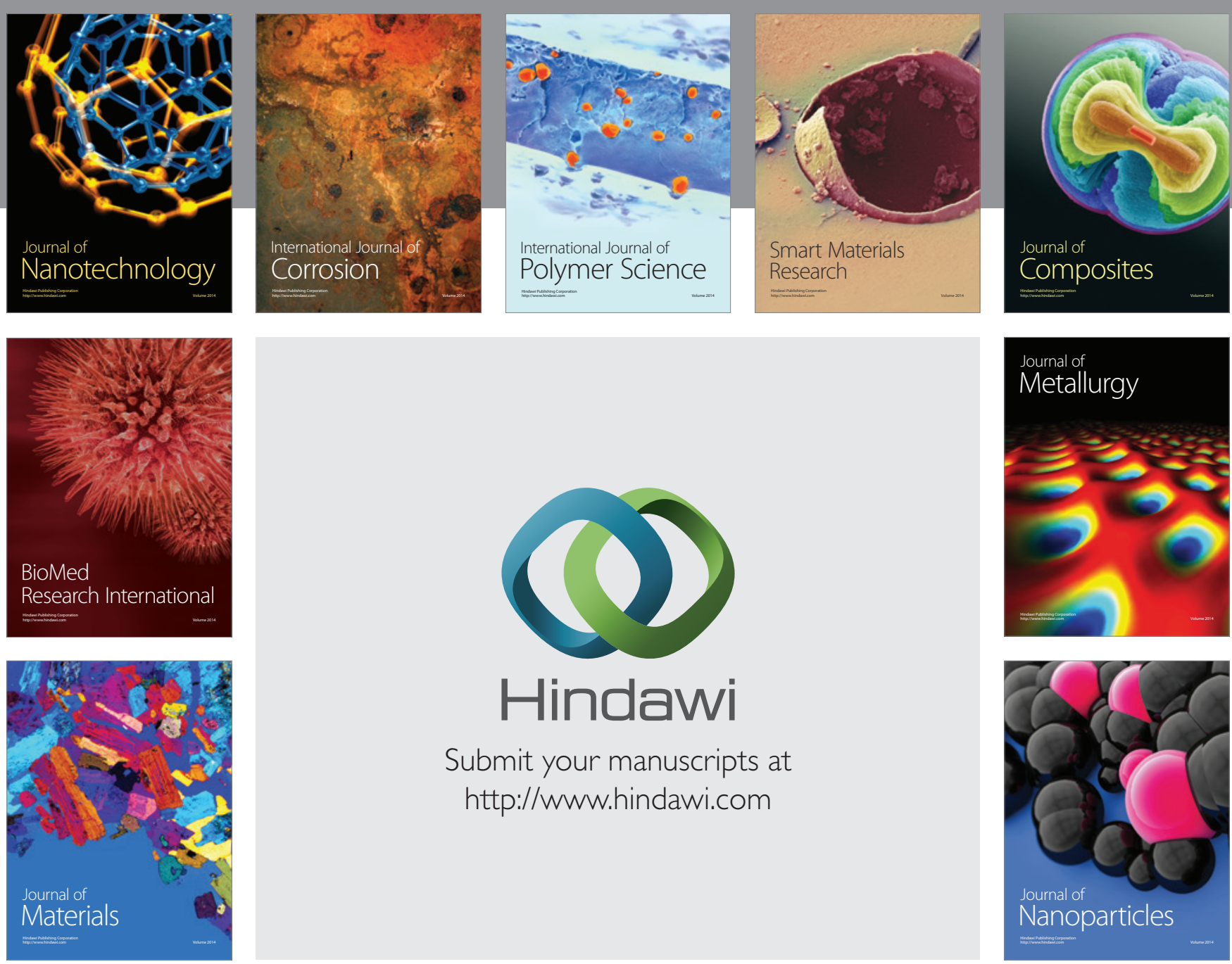

Submit your manuscripts at http://www.hindawi.com
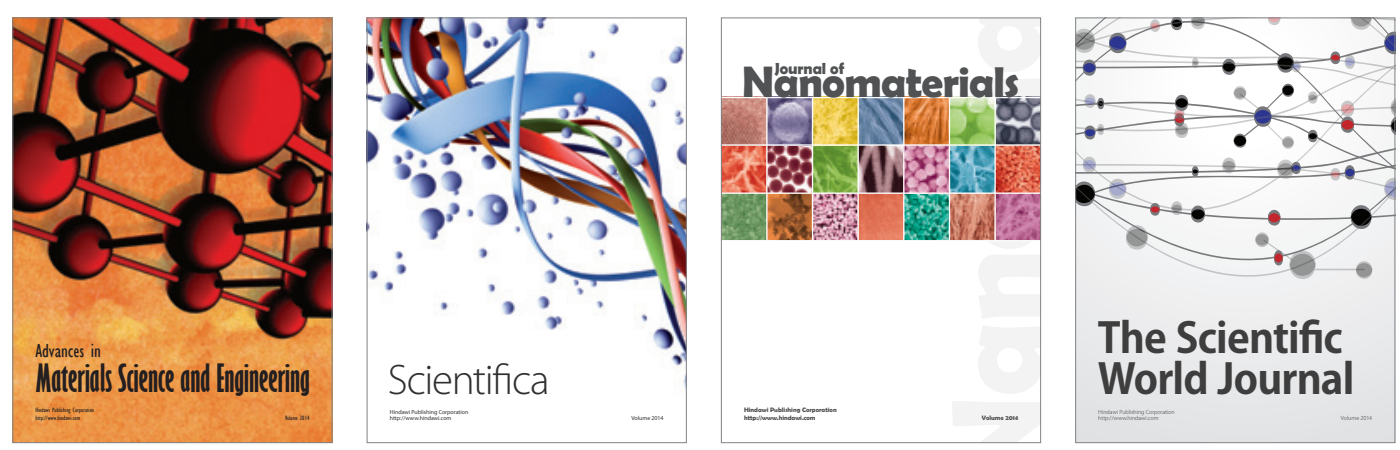

\section{The Scientific World Journal}
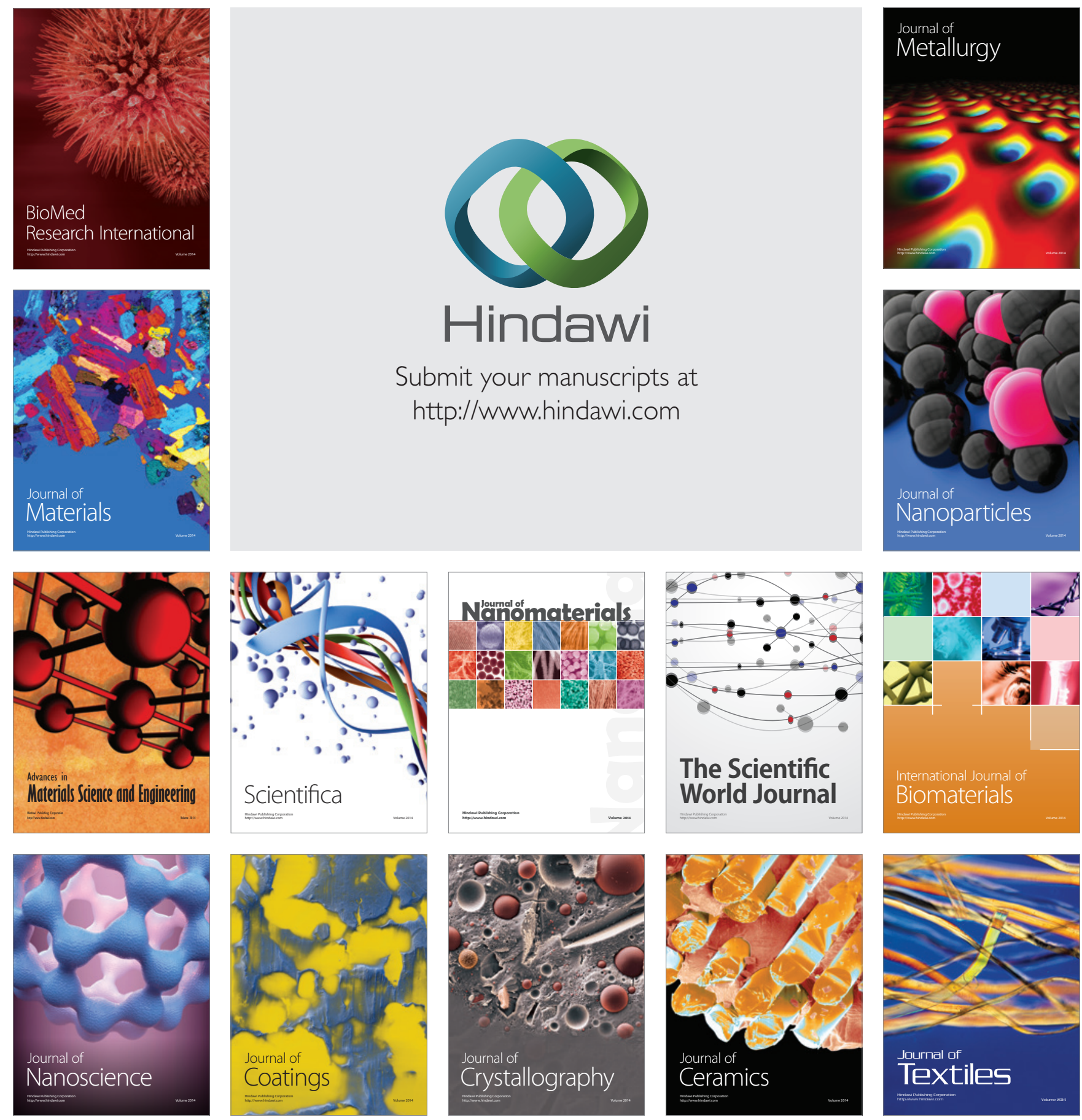